OPEN ACCESS

Edited by: Nuno Ferreira,

University of Sussex, United Kingdom

Reviewed by:

Elias Dinas,

European University Institute (EUI),

Vanessa Grotti,

University of Bologna, Italy

${ }^{*}$ Correspondence:

Sophia Zisakou szisakou@gmail.com

Specialty section:

This article was submitted to Refugees and Conflict,

a section of the journal

Frontiers in Human Dynamics

Received: 10 April 2021 Accepted: 22 June 2021

Published: 22 July 2021

Citation:

Zisakou S (2021) Credibility Assessment in Asylum Claims Based on Sexual Orientation by the Greek

Asylum Service: A Deep-Rooted

Culture of Disbelief.

Front. Hum. Dyn 3:693308.

doi: 10.3389/fhumd.2021.693308

\section{Credibility Assessment in Asylum Claims Based on Sexual Orientation by the Greek Asylum Service: A Deep-Rooted Culture of Disbelief}

\author{
Sophia Zisakou ${ }^{1,2 *}$ \\ ${ }^{1}$ Other, Athens, Greece, ${ }^{2}$ Independent Researcher, Athens, Greece
}

The aim of this article is to describe and analyze the main practices that the Greek Asylum Service applies to assess credibility in asylum claims based on sexual orientation. The analysis is based on a survey of 60 cases (interviews and first instance decisions). According to the results of the survey, the practices used could be divided into two categories. On the one hand, practices that do not conform with refugee law, the Common European Asylum System, and human rights standards, such as questions around sexual practices of the asylum seekers, stereotyped expectations about applicants' behavior and knowledge, and arbitrary assessments lacking any legal reasoning. On the other hand, practices that, at first sight, comply with international and European guidelines for credibility assessment but are based on an essentialist understanding of lesbian, gay, and bisexual identity. According to the research, applicants are expected to have passed through a hard process of self-realization which has to be accompanied, by default, by feelings of difference, shame, and suffering. In the article, the author critically reflects on the practices applied, concluding that this notion of sexual orientation as innate and defining one's identity, fails to take into account the intersections of gender, class, ethnicity, and race, and could lead to unjust judgments.

\footnotetext{
Keywords: credibility assessment, sexual orientation, asylum claims, Greek asylum service, stereotypes, sexual identity, right to self-determination
}

\section{INTRODUCTION}

Credibility assessment in sexual orientation (SO) asylum claims has always constituted a challenge for decision-makers in the absence of any broadly accepted approach to the issue. In contrast to other claims, where the applicant may be in a position to submit evidence, or answer questions around public events and incidents, that are known, accessible and verifiable, lesbian, gay, bisexual, and same-sex attracted asylum seekers that do not fit into the LGB categories (LGB+) in most of the cases do not have anything but their statements to prove the credibility of their accounts. Furthermore, while for all claimants it is difficult to elaborate on past experiences, often hard and traumatizing, LGB+ applicants need to present parts of their private life, which renders the process of the interview an extremely difficult and, in many cases, harmful experience (Millbank, 2009b).

These introductive remarks, assessed in combination with the particularities of the Greek asylum system, reveal the harsh reality that sexual minorities face to be granted protection. Following the European Union (EU)-Turkey statement signed in March 2016 (European Council, 2016), the asylum procedure in Greece was formed under the following binary scheme: A regular procedure in 
the mainland with extended deadlines, and a fast-track, border procedure in the five hot-spot islands (Chios, Lesvos, Leros, Kos, Samos) with stricter deadlines and less guarantees. Through an administrative decision, geographical restriction was imposed on those applying for asylum in the borders, limiting their freedom of movement to the respective island. This policy progressively leads to extreme overpopulation in the reception centers. Moria's camp in Lesvos, with a total capacity of less than 3,000 people, was hosting more than 21,000 asylum seekers in the beginning of 2020 (RSA, 2020).

Three years after the implementation of the EU-Turkey statement, in July 2019, the right-wing liberal conservative New Democracy party came to power. Anti-migration rhetoric, as part of New Democracy's political agenda, was promoted even before the elections. Consistent to their declarations, 5 days after the election, the Minister of Labor and Social Affairs revoked the circular regulating the issuance of social security number for asylum seekers, leaving children and vulnerable populations without access to the public health system (MSF, 2019). Progressively, in public debate the "refugee issue" was transformed into the "migration issue," undermining the need for protection of the people arriving in Greece. The new Minister for Migration and Asylum, Notis Mitarachi, made it clear from the very first moment that his priority was the limitation of the flows (Malichudis et al., 2020). Since the beginning of 2020, a plethora of reports and mounting evidence has been published on the use of pushbacks by the Greek Coast Guard to prevent refugees and migrants from accessing Greek territory (BVMN, 2020; ECRE, 2020; Human Rights Watch: Cosse, Eva, 2020; UNHCR, 2020). ${ }^{1}$

This political atmosphere highly affected the transformation of the national refugee legislation. After the January 1, 2020, the implementation of the new law for asylum introduced radical changes both in asylum procedures and in refugee status determination (RSD). ${ }^{2}$ These changes in law highlighted that the main priority of the Greek Government was the acceleration of asylum procedures, at any cost, in its effort to limit refugee and migratory flows. Strict procedural burdens and punitive measures, established by the new law, reduced safeguards for people seeking international protection (AIDA: Greek Council for Refugees, 2020). ${ }^{3}$ Among the changes, a catalogue of 14 safe countries of origin was drafted for the needs of RSD. ${ }^{4}$ Countries

${ }^{1}$ On 1st September 2020 the Minister of Migration and Asylum posted on his account on Facebook, celebrating, that there have been no arrivals on Lesvos island the last $3 \mathrm{wk}$.

${ }^{2}$ Law 4636/2019 (Government Gazette 169/A/01-11-2019) On international protection and other provisions.

${ }^{3}$ Extension of detention's time limit from three to 18 mo for asylum seekers, examination of unaccompanied children's applications under border's accelerated procedure, limitation of family unity and restricted definition of family members, limited access to legal remedy and legal aid, nonautomatic suspensory effect of the submitted appeals are only some of the law provisions that jeopardize asylum seekers' status and expose them to a severe danger of return without an individualized examination of their application.

${ }^{4}$ Common ministerial decision 1302/2019 (Government Gazette 4907/B/31-122019) National Catalogue of Safe Countries according to article 87 (5) of the law $4636 / 2019$. such as Algeria, Bangladesh, Gambia, Ghana, Morocco, Pakistan, Senegal, Togo, and Tunisia, where consensual same-sex acts are criminalized (Ramón Mendos, 2019), are considered safe countries of origin (Ministry of Migration and Asylum, 2021). ${ }^{5}$

This general rather hostile political climate toward refugees and the emphasis on the acceleration of the procedure, especially for those coming from "safe countries" and considered to submit bogus asylum claims, minimized the prospect of an individualized examination of an asylum application (AIDA: Greek Council for Refugees, 2020). However, as the current survey will show, with regards to credibility assessment in SO asylum claims, this factor is only one side of the problem. Apart from the bad practices that are connected with the particularities of the Greek framework and are usually against United Nations High Commissioner for Refugees (UNHCR, 2012) guidelines and Court's of Justice of the EU (CJEU) interpretation, implemented practices reveal the promotion of a European system, which is focused on an essentialist identity-based understanding of samesex sexuality and is willing to protect only LGB+ identities that comply with stereotypical expectations and can be therefore recognized as LGB+. This asylum adjudication system renders visible only certain types of expression and experiences that can be considered credible and obscures the subjectivity and the complexity of sexuality as an intersection of gender, class, ethnicity, and race. The latter, as previous researches have shown, is a common approach in SO asylum claims in Europe and raises concerns about the adequacy and the suitability of the guidelines and the methods being used to assess credibility at a European level (Gröndahl, 2020; Gustafsson Grønningsæter, 2017; Jansen, 2018; UKLGIG, 2018).

This article will be focused on the practices applied by the Greek Asylum Service (GAS) to assess credibility and will examine their compatibility with refugee law, the Common European Asylum System (CEAS) and human rights standards. It will further analyze how these practices, even when they do not seem to contradict with the normative framework and the guidelines, could lead to unjust adjudications and exclude refugees who do not conform with a biased notion of a fixed and immutable LGB+ identity. Specifically, the article will examine, through an intersectional approach, the nature of the questions asked, the use of stereotypes, the use of evidence, and the compliance of other practices with International and European law. Finally, according to the findings of the survey and the literature, the author will critically reflect on the efficiency and the adequacy of the current guidelines and applied methods and will suggest some alternatives.

\footnotetext{
${ }^{5}$ According to articles 83 (9b) and 88 (2b) of the law 4636/2019 when the applicant comes from a safe country of origin, their applications are examined through the accelerated procedure and are rejected as manifestly unfounded. According to GAS guidelines, at the beginning of the procedure the applicant is informed that their country is included in the catalogue of safe countries of origin and it is consequently presumed that they will not face any risk in case of return. It is further explained that the burden of proof to rebut this presumption lies with the applicant.
} 


\section{METHODOLOGY, AIMS, AND RESULTS}

\section{Motives and Aims of the Survey}

Working as a lawyer in the field of refugee law in Greece since 2016, either in borders or in the mainland, I have had the chance to assist and represent SO claimants and witness at first hand the practices that GAS applies to assess credibility. Through this, I became progressively concerned about the suitability and the effectiveness of the applied methods. SO claimants, as third-country nationals and sexual minorities, in Greece face intersectional systemic discrimination and an unhospitable framework that requires proof of their sexuality. This observation, in combination with the scarce research in the topic of sexual orientation and gender identity (SOGI) asylum claims in Greece (Avgeri, 2021), were my main motives to conduct this study. I hope that this study's account of practices applied in Greece and the illustration of their unjust outcomes will contribute to the voices advocating for a review of the relevant guidelines, in compliance with queer, feminist, and postcolonial theories. It should be noted that this survey was conducted independently, without receiving any funding, in the absence of relevant opportunities.

\section{Methodology and Limitations}

This study consists of a qualitative analysis of 60 cases of LGB+ applicants, whose claim for asylum was submitted between July 2016 and February 2020, collected between February 2018 and March 2020. All 60 asylum applications were rejected in the first instance because applicants' accounts were considered internally non-credible (non-credible SO or non-credible incidents and facts of the narrative). ${ }^{6}$ Second instance examination in the Greek asylum system is conducted by Appeals Committees without a hearing of the applicant and, for this reason, second instance decisions were beyond the scope of the present article. Furthermore, according to the domestic law, in case an application for asylum has been accepted, the beneficiary does not have access to the reasoning of the decision. Consequently, positive decisions were out of consideration. ${ }^{7}$ The files analyzed were collected either from my archive, either were cases that were handled by my close colleagues throughout their practice as refugee lawyers. It should be noted that GAS, as happens in the majority of the European countries, does not collect statistical data about asylum applications based on SO and does not possess an organized archive of cases. In an effort to study a representative sample of the methods and criteria that GAS applies to assess credibility, the cases studied were determined by a large number of Regional Asylum Offices both in the mainland (35 cases in total) and on the five hotspot islands (25 cases in total). Trying to avoid further limitations and bias, I did not proceed to any selection process of the decisions studied, based on qualitative criteria regarding the applied methods.

${ }^{6}$ Internal credibility is the first stage examined in an application according to the GAS practice. It concerns the consistency of applicant's statements and the assessment of the plausibility of their narrative. It is followed by the examination of the external credibility which covers the verification of the applicant's story according to the country-of-origin information.

${ }^{7}$ Law 4636/2019, article 82(3).
Consequently, all the cases collected, where the applicants consented, were included in this study. However, due to lack of study of positive decisions and the limited number of the sample, the article's findings provide a preliminary indication of the methods and practices that GAS applies to assess credibility.

This survey is restricted to a qualitative analysis and no quantitative data are provided. The sample's analysis took place between November 2019 and June 2020. To study the practices applied, a document-based research has been pursued, focused on asylum interviews and first instance decisions. Through the analysis of the material, I proceeded to a three-stage evaluation. First, I was focused on examining whether the GAS applies practices that do not comply with the refugee law, the CEAS and human rights standards and on what frequency. Second, I have attempted to assess how GAS applies the dominant model of credibility assessment which focuses on the examination on experiences of Difference, Stigma, Shame and Harm-the so-called DSSH model-that is proposed by both UNHCR and the European Asylum Support Office (EASO) and what is the outcome of its application. Third, I have focused on the observation of how variables such as the applicants' gender, class, ethnicity, and race interfere with the application of the aforementioned practices (especially with the proposed model of credibility assessment) in an effort to study the issue of credibility assessment in an intersectional approach. The hypothesis behind the study, which has steamed from my experience as a refugee lawyer, was that GAS applies to a great extent forbidden practices and that the alternative methods of credibility assessment aggravate the injustices of the procedure by setting arbitrary standards, based on stereotyped notions about LGB identity, that disproportionately burden the applicants of lower class and women.

All the applicants, whose files are included in the research, provided their written informed consent. Given the vulnerable status of refugees, for protection reasons, during the study, I ensured applicants' anonymity by maintaining, in some cases, only their country of origin. Even though I did not conduct personal interviews with the applicants or the decision-makers, it is possible that at some points I provide some information and arguments based on my general experience or my interaction with asylum seekers or the authorities. However, this lack of ethnographic fieldwork deprives from the applicants the possibility of expressing their own voices and their experiences, expressions, and notions about sexuality and gender are intermediated by the transcripts of their asylum interviews.

\section{Overview of the Results}

To provide a short overview of the results, the practices detected to be applied by GAS to assess credibility in SO asylum claims could be distinguished into 1) practices that do not comply with refugee law, the CEAS, and human rights standards and 2) practices that even though they do conform with the proposed guidelines could amount to unjust adjudications and have received substantial criticism by academics and researchers. ${ }^{8}$

${ }^{8}$ The results of this survey were first presented in the SOGICA Final Conference, organized by Sussex University, in July 2020. Participants' comments and questions were invaluable for the drafting of the present article. 
Specifically, on the one hand, it has been observed that in 16 cases applicants were asked to provide details about their sexual practices, in 28 cases stereotyped notions about LGB+ persons such as previous marriage, lack of knowledge about LGBTI organizations, and penal provisions in the country of origin were among the reasons of rejection, in two cases applicants were not allowed to submit voluntarily non-pornographic evidence, in 15 cases interview was focused on the exact date and time of the events and even small discrepancies were assessed as lack of credibility and, finally, in five cases applicants were arbitrarily disbelieved without a legal reasoning included in the decision. These practices, which will be analyzed in the following sections one by one, contravene with the existing legal framework and should be avoided. On the other hand, in 39 cases, applicants were disbelieved because they were not in a position to elaborate on how and when they realized their SO, on what occasion and how this realization shaped their identity. In such cases applicants were expected to express deep feelings about their partners, to feel different in their countries, and to narrate a "painful journey." These expectations that seem to conform with the guidelines are based on a generalization that all refugees perceive their sexuality in the same way and are described in the research as secondgeneration stereotypes, in order to be distinguished from the traditional, first-generation stereotyped expectations. According to the study, factors such as gender, class, ethnicity, and race that intersect with sexuality were not taken into account by GAS and contributed to produce more exclusions. The bad practices observed, as it follows from the presentation of the results, can overlap and, in some cases, more than one out of the aforementioned practices constituted bases for the rejection.

\section{Contribution of the Research}

Finally, this article's contribution is original in three ways. First, it increases the existing knowledge base by providing empirical evidence of the applied method to assess credibility by GAS, an under-studied topic of particular importance because of the high number of asylum applications in Greece. Second, it contributes to the literature by focusing on the current tendency noticed in Europe, especially following the $A, B$ and $C$ judgment to shift the focus of the assessment from practices to feelings accompanied by an identity-based perception of SO. Last, it provides a point of view by examining the legal topic of credibility assessment through the lens of queer, feminist, and postcolonial theory, highlighting the fact that the system of credibility assessment of the applicants' sexual orientation has been developed through the past decades with indifference toward all relevant literature and social theories that could greatly assist in building a just and inclusive system.

\section{PROVING SEXUAL ORIENTATION IN ASYLUM CONTEXT: THE UNRESOLVED CHALLENGE}

Rejecting SO asylum applications due to lack of credibility is a shift in case-law which is noticed extensively in asylum adjudications after the abolishment of the discretion requirement (Millbank, 2009a, Jansen, 2018, Gustafsson
Grønningsæter, 2017). At the EU level, the CJEU abolished the requirement of concealment of SO in the country of origin in the $X, Y$ and $Z$ judgment. ${ }^{9}$ Before this, claimants' SO was considered credible but, according to practice, they could be returned to their country of origin if it was determined that they could conceal their SO. Following the CJEU's judgment, and since the concealment is not an option, in most of the cases SO asylum claims are rejected due to lack of credibility (Jansen, 2014). This practice, apart from a turn in the case-law, serves the Greek Government's aim of acceleration: Since credibility is the first stage of the examination of an asylum application, if the asylum seeker does not prove the credibility of their claim, the decisionmaker does not need to proceed to examine the well-founded fear and the persecution grounds in the country of origin, during both the interview and the decision-drafting, which can be translated to a much shorter and less demanding inquiry.

However, it should be noted that proving someone's SO is by default a problematic requirement. Sexual minorities in heteronormative societies have historically experienced extensive doubting of their right to self-determination. Questioning one's stated SO can be offensive, traumatic, and humiliating (Struthers, 2020). In many cases LGB+ individuals face harmful experiences of a society that challenges their sexuality as something that needs therapy and can be corrected (Rehaag and Evans Cameron, 2020). What is more, not even scholars who profoundly study human sexuality have concluded on what SO exactly means and there is little consensus on the topic (Rehaag and Evans Cameron, 2020). Considering the aforementioned uncertainties, if someone in daily life is wondering about a person's SO, the only safe method to know is to ask them about it and rely on their words (Jansen, 2018; Jansen and Spijkerboer, 2011; Gustafsson Grønningsæeter, 2017). Self-identification, as an aspect of the right to privacy, is part of the European human rights system. ${ }^{10}$ However, in asylum procedures neither UNHCR nor the CJEU accept self-identification as an adequate element for the establishment of an asylum seeker's credibility. For UNHCR self-identification is an indication of someone's SO and for the CJEU it is the starting point of the procedure (UNHCR, 2012). ${ }^{11}$

According to the $A, B$ and $C$ judgment, in which the Court elaborated on SO evidentiary matters, implicit questions around sexual practices are against the applicant's right to privacy and are prohibited. ${ }^{12}$ Respectively, the reproduction of films with sexual content, and the applicant's submission to medical and psychological tests, are not in conformity with the right to dignity and cannot be used as means of evidence in asylum procedures. ${ }^{13}$ However, in the $F$ judgment, the CJEU ruled that $\mathrm{SO}$ can be the subject of an expert's examination, as established in

\footnotetext{
${ }^{9}$ Joint cases C-199, C-200 and C-201/12 X,Y and Z v Minister voor Immigratie, Integratie en Asiel [2013] EU:C:2013:720.

${ }^{10}$ Van Kuck v Germany App no 35968/97(ECtHR, 12 June 2003) para 69.

${ }^{11}$ Joint cases C-148, C-149 and C-150/13 A, B and C v Staatssecretaris van Veiligheid en Justitie [2014] EU:C:2014:2406, para 49.

${ }^{12}$ Joint cases C-148, C-149 and C-150/13 (n 11) para 64.

${ }^{13}$ Joint cases C-148, C-149 and C-150/13 (n 11) para 65.
} 
the Procedures Directive (Article 10). ${ }^{14}$ This assessment has to be in compliance with human rights standards. ${ }^{15}$ The CJEU did not define though, what type of assessment could help an expert determine someone's SO.

Although the CJEU's opinion was clear with regards to the use of medical and psychological examinations and intrusive questions that are prohibited, this was not the case for the use of stereotypes. According to the CJEU, stereotypes can be a useful element in credibility assessment. However, they cannot be the sole basis for the rejection of the applicant's credibility. ${ }^{16}$ Even though all the decisions studied for the needs of the present article were drafted after the $A, B$ and $C$ judgment, practice proves that methods being used do not adequately conform with the CJEU's interpretation, and steps toward a fair and harmonized CEAS are very slow, especially in topics where the Court's opinion was not sufficiently clear.

\section{CREDIBILITY ASSESSMENT BY GAS: THE PRACTICES APPLIED}

Before proceeding to the substantial analysis, a general framework about the first instance examination process and the role of the implicated actors should be presented. In the asylum procedure, GAS administrative personnel is responsible for the conduct of the interviews. In 2016, as it was predicted by the former law for asylum, EASO's staff could assist GAS to conduct the interviews and draft opinions in the border procedure, while the issuance of the first instance decisions remained responsibility of GAS. ${ }^{17}$ In 2019, EASO's role was extended to the mainland and the regular procedure. ${ }^{18}$ The case workers' educational and professional background varies greatly: GAS case workers are chosen through the standard process of civil servants' recruitment, which only requires a university degree. EASO's interim case workers are recruited through a more competitive process due to the higher remuneration package offered by the agency, but they are also not required to have a legal background but only a university degree, preferably in humanitarian studies, while professional experience with refugees or relevant studies are desirable but not required.

In terms of training, EASO case workers pass through a 1-mo general introduction training before they begin, which is not foreseen for GAS case workers. During their service, all case workers have the chance to attend different educational seminars, conducted either by EASO or by UNHCR. Among them, a training by EASO for SOGI asylum claims is included, which is focused on the presentation of the DSSH model. However, not all the case workers have attended it.

\footnotetext{
${ }^{14}$ Directive 2013/32/EU of the European Parliament and of the Council of 26 June 2013 on common procedures for granting and withdrawing international protection [2013] OJ L 180.

${ }^{15}$ Case C-473/16 F v Bevándorlási és Állampolgársági Hivatal [2018] EU:C:2018:36, paras $28-29$.

${ }^{16}$ Joint cases C-148, C-149 and C-150/13 (n 11) para 62.

${ }^{17}$ Law 4375/2016, article 60(4).

${ }^{18}$ Law 4636/2019, article $77(1,2)$.
}

Unlike EASO, UNHCR is not implicated in the adjudication. UNHCR asylum experts as quality focal points are having a subsidiary, guiding role in the RSD. ${ }^{19}$

Furthermore, it should be noted that, with regards to SO asylum claims' examination, GAS has not published specific guidelines for the procedure. The only relevant material, apart from UNHCR guidelines that are publicly available, is two model questionnaires that were drafted by UNHCR and EASO for the needs of the assessment and which provide some general guidance and are not extensive (both questionnaires are less than five pages). According to the questionnaires, questions around sexual practices of the applicant should be avoided. Instead, as it will be analyzed in the article, the examination should be focused on the self-realization process of the applicant's $\mathrm{SO}$, which according to the material is accompanied by feelings of difference, and ends up in the formation of an identity.

\section{Intrusive Questions About Sexual Practices of the Applicant}

Even though both UNHCR guidelines and the CJEU in the $A, B$ and $C$ judgment leave no space for misinterpretation concerning the issue of questions about asylum seekers' sexual practices, as they both consider that such questions violate applicant's right to private life and are forbidden (UNHCR, 2012), it has been observed that in 16 out of the 60 interviews analyzed applicants were asked to provide details about their sexual life. $^{20}$ Questions like, "Tell us some details from your first time," "How long did it take?" or "I want you to describe to me what you did when you met each other," were found in six cases. It should be noted that in a case where the applicant avoided the question and did not provide the information asked, the case worker insisted and asked the applicant again to describe his first sexual experience. Also, during the interview of a lesbian woman from Morocco, the applicant was asked to provide details about her rape, including whether she was sexually stimulated during her rape and how she felt while having sex with a man. In the case of a same-sex attracted woman from Iraq, the applicant was asked when and where she had her first sexual intercourse. The applicant responded that she had her first sexual contact in Greece and she was subsequently asked to explain the reasons why she did not have any previous sexual experience. In another case, a gay man from Pakistan was asked how often and where he used to have sexual contacts. Moreover, in a case of a gay man from Benin, the applicant was not only asked to provide details about his sexual contacts, but his denial to do so-because as he stated in his interview "this information is private"-was the reason for his claim to be considered non-credible.

What it can be concluded from the results of the study, is that the frequency of this practice, in over one quarter of the cases (16/ 60 ), is very high considering it being a forbidden method. The abolishment of questions around applicant's sexual practices guarantees individual's fundamental rights and it is,

\footnotetext{
${ }^{19}$ Law 4636/2019, Article 73.

${ }^{20}$ Joint cases C-148, C-149 and C-150/13 (n 11) para 64.
} 
undoubtedly, welcomed. The use of intrusive questions by the examining authority and the rejection of the applicants' accounts as non-credible because of their refusal to share this information, violate applicants' rights to dignity and privacy (UNHCR, 2013). Applicants should never be asked about their sexual life, when and how they had their first and following same-sex sexual contacts.

However, decision-makers, in an effort to comply with the abovementioned guidance, have shifted the focus of questions from sexual practices to feelings, with the latter tending to turn into the sole field of examination (UKLGIG, 2018; Jansen, 2018; Gustafsson Grønningsæter, 2017). In this transition from practices to feelings, questions such as When and how did you realize your SO? How did you feel about it? How do you feel about your difference? What are your feelings towards your ex-partners? as this survey will show, take up a disproportionately large part of the credibility assessment, despite seeming as not having a right answer. Although an applicant should never be asked to provide details about their sexual experiences, the feelings-centric perception that emerged after the $A, B$ and $C$ judgment suffers from a bias, as SO for some applicants is connected more with practice than with one's identity and feelings (see below section about Second-Generation Stereotypes; Jansen, 2018; Gustafsson Grønningsæter, 2017). This understanding of same-sex sexuality is based on a dangerous generalization that every refugee perceives their sexuality in the same way. However, in an individual-basis examination, according to Procedures (Article 13) and Qualification (Article 4) Directives, the applicant should have the right to articulate their narrative without having to confront and deconstruct the preconceived notions of the decision-makers. $^{21}$ The CJEU's abolishment of intrusive questions should not be arbitrarily interpreted as if SO is only a matter of identity and feelings. This could amount to false conclusions about the claim's credibility and unfairly exclude applicants from receiving international protection.

\section{Stereotypes}

In contrast to questions regarding sexual practices, the CJEU and UNHCR are not so clear with regards to the use of stereotypes in the assessment. According to the CJEU, although an assessment based on stereotyped notions cannot be the sole basis of a rejection, as this would be contrary to an individual-basis examination, stereotypes, such as the applicant's appearance or the previous knowledge of organizations for the protection of the LGBTI rights in their country of origin, can be a useful element during the examination of the applicant's credibility. ${ }^{22}$ It is worth mentioning that the CJEU in $A, B$ and $C$ examined only the conformity of the practice with CEAS and not with human rights. UNHCR's position around the topic was that the practice is not

\footnotetext{
${ }^{21}$ Directive 2011/95/EU of the European Parliament and of the Council of 13 December 2011 on standards for the qualification of third-country nationals or stateless persons as beneficiaries of international protection, for a uniform status for refugees or for persons eligible for subsidiary protection, and for the content of the protection granted [2011] OJ L 337.

${ }^{22}$ Joint cases C-148, C-149 and C-150/13 (n 11) paras 60-64.
}

by itself against human rights, but it depends on the way it is applied (UNHCR, 2013).

\section{First-Generation Stereotypes}

Prior to $A, B$ and $C$ judgment domestic authorities were excessively using stereotypes with regards to asylum seekers' assumed knowledge, behavior, and appearance. Amongst the typical stereotyped notions were the anticipation for the gay men to look feminine and the lesbian women masculine, the expectation for the claimant to be familiar with the gay scenes, LGBTI organizations, and terms, to participate in gay parades, to know about the criminal sanctions in the country of origin, to not be married or have children, to avoid a risky behavior, and to engage in same-sex acts motivated by noneconomic reasons (Jansen and Spijkerboer, 2011). The catalogue is long and, in many cases, the expectations of the decision-makers are extremely absurd. These "old" stereotyped notions that could be described as a first generation of stereotypes continue to be applied during examination (ECRE, 2017; Jansen, 2018). However, their extensive use as a basis for non-credibility has been reduced in many European countries (Gustafsson Grønningsæter, 2017), especially after the $A, B$ and $C$ judgment of the CJEU, which constituted a benchmark for the practices applied in credibility assessment. Meanwhile, new stereotyped notions and expectations for LGB+ persons seem to be established in asylum procedures, as it will be analyzed below (see section: Second-Generation Stereotypes).

According to the results of the survey, out of 60 cases, 28 negative decisions contained in their reasoning stereotypes connected to applicant's assumed knowledge and demeanor. The claim of a lesbian woman from Cameroon was assessed as non-credible because, inter alia, her first same-sex relationship was at the age of 39 and she was a mother of three children. This stereotyped notion of parenthood and previous marriage as incompatible with same-sex SO was observed in four other cases. A gay man from Pakistan did not know the provisions of the penal law against homosexuality. A gay man from Ivory Coast did not know about LGBTI organizations and authorities' treatment toward LGBTI. A same-sex attracted man from Sierra Leone did not identify himself as a gay, although he explained the reason: This term was totally unknown in his community until 2010, and they used the term man-to-man to describe men who had same-sex contacts. A lesbian woman from Morocco was not expected to speak about her relationships with women because it was too risky in Morocco's society. A gay man from Cameroon had only paid sexual contacts and another applicant from the same country had his first relationship at the age of 34, when previously all of his sexual contacts were with women. All the above-mentioned stereotypes constituted indications for GAS to conclude that the applicants were not able to establish the credibility of their SO.

Even though stereotypes based on asylum seekers' appearance have not been detected in the files, relevant surveys on the topic prove that there is a tendency in decision-making according to which even though adjudicators have not stopped assessing credibility based on how the applicants look like, they have stopped referring to their appearance in the reasoning of the 
decision and rather base their conclusions on legally permissible reasons according to the guidelines (Rehaag and Evans Cameron, 2020). Although such a conclusion about assessment based on applicant's demeanor cannot be drawn with certainty through the present study, this scenario seems possible, especially considering the number of decisions where a reasoning about the decisionmaker's conclusions was totally lacking (see below section: Other Practices).

It is notable that, in contrast with intrusive questions, which is an absolutely forbidden practice, the use of first-generation stereotypes in credibility assessment is more regular and extensive and reveals the need for clear guidance (ECRE, 2017). Based on $A, B$ and $C$ judgment and UNHCR guidelines, in the reasoning of a decision studied, it was supported that stereotypes could be used when they are in favor of the applicant. However, it is strongly suggested in the present article that stereotypes should never hold a place in legal judgments, not even when they can only be used in favor of an applicant. Stereotypes are intrinsically subjective, and they are shaped according to one's cultural background. They, therefore, constitute a nonmeasurable and noncontrollable variable, whose consideration in legal reasoning could very easily lead to injustice. In addition, the use of stereotypes for credibility assessment establishes a distinction between the conforming and the nonconforming applicant: the applicant who conforms with stereotyped notions about their $\mathrm{SO}$ will receive a more lenient examination of their asylum claim and a lower standard of proof. This distinction is unfair, because conforming to fixed, predetermined notions of LGB+ identities does not amount to any substantial evidence of credibility and nonconformity should not be indirectly penalized. Finally, the use of stereotypes in decision-making could incite nonconforming applicants to adjust their behavior and statements during the interview with the purpose of being rewarded with a lower standard of proof, a process that is humiliating and could be severely traumatizing. For these reasons, stereotypes should never be considered a "useful element" or constitute a basis for legal judgments, which need to be based on facts and evidence (Gomez, 2014).

\section{Second-Generation Stereotypes}

While traditional stereotypes continue being used as a practice for assessing credibility by GAS, new stereotypical ideas about sexual minorities seem to emerge. In the majority of the cases $(39 / 60)$, applicants were expected to perceive their SO as an element that defines their identity, to express deep feelings about their partners and to refer to more than periodical same-sex contacts to be believed. They were expected to have passed through a process of self-realization that, according to the decisions analyzed, should be accompanied, by default, by a negative feeling, and the applicant should be able to elaborate on this. The applicant had to be in a position to specify the time of self-discovery, which should have been at an early age, to provide details about the experience and express an emotional and well-structured narrative. Applicants were expected to present an account of shame and difference, describing a "painful journey," since relating their sexuality with positive sentiments such as joy and pleasure was assessed as a basis for disbelief. These notions, which are based on a generalization and a presumption that every refugee perceives their sexuality in the same way, could be described as "second-generation stereotypes."

Even though the theory around the stages of realization and expression of one's SO is not new-it was in the early 1980s that Cass proposed a model of homosexual identity formation based on different stages (Cass, 1979) — in recent years it is extensively used as the basis for an alternative tool used in SO credibility assessment (Jansen, 2018; UKLGIG, 2018; Gustafsson Grønningsæter, 2017). In 2011, the Difference, Shame, Stigma, Harm (DSSH) model was first introduced as a method to assess credibility in SOGI asylum claims by moving the weight from external behavior of the applicant to their inner emotional journey by exploring their lived experience of difference, stigma, shame, and harm (Hungarian Helsinki Committee et al., 2015). This model has been endorsed by both UNHCR and EASO (UNHCR, 2012; EASO, 2018). According to EASO's guide, “the model is based on the notion that there are some basic characteristics or elements that are likely to be common to people acknowledging a gender or sexual identity that is contrary to the heteronormative societies in which they live" (EASO, 2018; Hungarian Helsinki Committee, 2015). Both GAS (provided by UNHCR) and EASO internal guidelines for the examination of SO asylum claims suggest to the case workers to investigate these fields during credibility assessment, even though GAS model questionnaire does not refer directly to the DSSH model.

In particular, in GAS model questionnaire, there is a whole section under the title "Identity" where questions around the process of self-realization are included, such as: "When did you realize that you are homosexual? How did you realize your SO? How did your life change after realizing that you are homosexual?" Furthermore, as it is suggested in the model questionnaire, the case workers should ask applicants to elaborate on their feelings and experience of difference, seemingly referring to a harsh and painful experience. Questions as "How did it feel when you realized that you are homosexual?" or "How did you feel being a homosexual in your country of origin?" are proposed. On the other hand, in EASO model questionnaire that is addressed to EASO's case workers, seconded to GAS, the DSSH model is clearly mentioned. In the section "Sexual Orientation and Self-realization" are included questions as: "What are the characteristics you would say define you as a person? When did you realize that you are interested in men/women? How old were you when you started realizing that you are interested in men/women/both? Did something specific happened and you realized that you are a homosexual?" Furthermore, questions around applicants' feelings of difference such as "What kind of feelings or thoughts did you go through when you realized that you are interested in men/ women? Did your life change in any way once you realized that you are interested in men/women? How were you feeling as a child?" are proposed.

The main idea of the tool is to "[h]elp the decision maker to ascertain the applicant's sexual orientation or gender identity, rather than focus on sexual practices" and is based on a "fourstages test" (Chelvan, 2013). Even though the CJEU in the $A, B$ and $C$ judgment prohibited explicit questions around sexual 
practices, medical and psychological examinations as evidence and prevented the decision-makers from using stereotypes, it did not provide further guidelines on how the authorities could assess applicants' credibility (Chelvan, 2014). The inclusion of the tool in different domestic adjudications could be considered a positive way to follow the $A, B$ and $C$ judgment and, on a first level, it is welcomed. However, this perception on which the model is based, that there are universal characteristics of sexual minorities and the idea that the discovery of one's sexuality is a linear process that starts from confusion and denial, ends with sentiments of self-worth, and leads to an identity synthesis, is rather a notion based on Western male sexual development and does not apply to everyone (Gustafsson Grønningsæter, 2017; Jansen, 2018, Berg and Millbank, 2009, Giametta, 2017). Expecting from the applicants to narrate an account of shame, difference, and suffering in their country of origin oversimplifies their experiences, ignores the intersections of sexuality with gender, class, ethnicity, and race, and enhances a dichotomy between modern, progressive Western societies and premodern, regressive countries of origin (Giametta, 2017; Shakhsari, 2014; Saleh, 2020).

\section{Erasing the Diversity: An Essentialist Conception of a Fixed and Immutable Sexual Identity}

According to the DSSH model, "being LGB is a current identity" and does not refer "only to sex" (Hungarian Helsinki Committee et al., 2015). The author of the model suggests that decision makers must explore not just "the applicant's conduct, but also the emotional and affectional component to sexual identity" (Chelvan, 2013). This notion of identity was among the main bases of disbelief on part of GAS. According to the decisions studied, the applicant had to be in a position to elaborate on how they perceived their sexual identity, how realizing their SO shaped their identity, and how their same-sex attraction was related not only to sexual practices but also to feelings for their partners. They had to be able to identify using the LGB terms, because otherwise this was interpreted as evidence for lacking of a coherent understanding of their sexual identity.

Specifically, in 10 cases applicants did not perceive their SO as a fundamental part of their identity or were hesitant to selfidentify as LGB+, which were indications for disbelief for GAS. A gay man from Cameroon "was having sexual attraction to men, without being in a position to elaborate on his true sexual identity." A gay man from Guinea "was not able to elaborate on how the realization of his SO changed his identity, but he was repeating that he knew that he was gay." A gay man from DRC was having same-sex sexual contacts for money, "without this being an important part of his identity." A gay man from Pakistan "was having periodically same-sex relationships without this being an important part of his identity." Furthermore, a married woman from Iraq could not understand and respond to the question: "How do you self-identify, as a lesbian or heterosexual?" All the aforementioned examples were used as arguments by GAS to reject the applicants' claims.

In addition, in 17 cases, applicants were expected to express deep feelings about their partners and not to simply refer to sexual experiences. Lack of such accounts was perceived as contradicting to the idea of a coherent and immutable sexual identity and resulted in negative decisions. A gay man from Cameroon "was mainly focused on sexual intercourse, without referring to emotions" and a lesbian woman from Morocco "was not in a position to express affection and emotions towards the woman she was in relationship with." A lesbian woman from Cameroon "was not able to provide details of how she felt about her first relationship and her statements were vague and not concrete." A gay man from DRC who was having sexual contacts with his teacher, according to the reasoning of the decision, was doing this for money and not because he had true feelings. A gay man from Bangladesh, in the question of how he felt toward his boyfriend, answered that they used to spend time together, they were going out for dinner, and he used to feel nice with him. These statements though, according to the decision-maker, "were vague and describe a friendly relationship."

How and whether sexuality and SO constitutes one's identity is not a new question in social sciences. Already in the 1970s and the 1980s the theory of the social construction suggests that sexual identity is not a universal category and focus is given on examining its cultural and historical composition. According to Fuss, homosexual identity emerged in Western societies along with the rise of industrial capitalism, not until the 17th century, and, therefore, there is a distinction between same-sex conduct, which is "universal" and homosexual identity "which is historically specific" (Fuss, 1989). According to Elliston, the idea that sexual orientation is something that the individual "is," rather than "does" is a recent historical development in EuroAmerican societies (Elliston, 1995). Elaborating further on the social construction theory, in 1990 Butler introduces the performativity theory according to which gender and sexuality are not perceived as preexisting, coherent, and stable identities but are constituted through the practice of iterative performances. Despite the fact that the different theories around the formation of the identity have been expressed more than $30 \mathrm{yr}$ ago, they seem to have been totally ignored throughout the establishment of a method of credibility assessment.

Instead, an essentialist view of sexual identity, as an innate characteristic, which is something more than sexual practice and defines the subject, predominates in the procedure (Giametta, 2017; Lewis and Naples, 2014; Hertoghs and Schinkel, 2018; Avgeri, 2021; Ricard, 2014). However, this normative understanding of a fixed predetermined identity obscures the complexity of applicants' subjectivity (Nasser-Eddin et al., 2018; Shuman and Bohmer, 2014; Saleh, 2020; Ricard, 2014). By promoting a specific perception of identity, which is rendered visible and becomes part of a credible account, other experiences and perceptions of sexuality are being erased, become invisible, and are, therefore, considered non-credible (Shuman and Bohmer, 2014; Saleh, 2020).

GAS operates with this conception of identity that is strictly and narrowly defined and is something more than sexual practice. Indicatively, in the case of a gay man from Cameroon, who during his interview provided a detailed narrative about how he used to be sexually stimulated when he was playing with other boys or when he was dreaming of having sex with a man, his account was rejected as non-credible because he could not understand and was not in a position to elaborate on how his SO shaped his identity. 
This tendency echoes what Foucault (1978) emphasized in the History of Sexuality: Law is regulating what should be told and consequently what exists. All the rest, that do not fit into the Service's understanding of a sexual identity, which, as the examining authority, interprets and applies the Refugee Convention, are erased as bogus claims and non-credible experiences. GAS, as the interpretative authority, intermediates and shapes how a credible narrative about same-sex sexuality should sound. As Butler (2005) describes it, what distinguishes experiences is not their truth, since there is no true-speaking voice or unmediated account, but the authority that intervenes and makes them more or less visible and intelligible.

However, practice proves that subjects' experiences are nuanced and complex, since subjects precede the fixed, predetermined identity and not the opposite (Saleh, 2020). There are different examples around the world where homosexuality tends to be perceived rather as conduct instead of an identity (e.g. hausa men in Nigeria, hijras in India, kathoeys in Thailand, see in detail (Katyal, 2002; Jansen, 2018)). Indicatively, Nasser-Eddin, Abu-Assab and Greatrick (2018) argue that this identity-focused perception ignores that sexuality is an intersection of gender, race, religion, age, and colonial history of the country of origin, excluding the experiences and the expressions of sexual minorities in Middle East and North Africa region. Instead, they suggest the induction of the term Sexual Practice and Gender Performance (SPGP) as a more suitable and inclusive term than SOGI and LGBTI.

Furthermore, even though applicants in the present study were expected to identify with LGB terms of sexuality, to be believed, this does not seem to correspond to applicants' experiences: These terms, as the idea of identity, have been developed in mainly urban, Euro-American contexts by educated individuals, and are themselves culture-specific. In many cases there are no such terms in the applicants' maternal languages or they cannot be translated (Nasser-Eddin et al., 2018; Shuman and Bohmer, 2014; Giametta, 2017). In addition, these terms, as the idea of SO being part of one's identity, in postcolonial era are identified with West civilization and are not always welcomed (Katyal, 2002). Consequently, in some cases, it is preferred by individuals to be identified with different terms used in local communities to express same-sex attraction, as an act of resistance to the dominance of the Western culture. In Indonesia, for example, some same-sex attracted Muslim men use the terms banci or bencong and usually are getting married and have children (Boellstorff, 2005). In India and Thailand, similarly, many same-sex attracted women self-identify as "women who love women" rather than "lesbians" (Blackwood and Wieringa, 2007; Dave, 2011).

What can be concluded from the above is that this normative understanding of a fixed and immutable sexual identity excludes a large number of same-sex attracted individuals, oversimplifies their experiences by erasing their diversity, and can lead to unjust conclusions about one's credibility.

\section{The Linear and Hard Process of Self-Realization}

In the majority of the cases studied (39/60), applicants were asked to provide details about how and when they realized their sexual orientation and on what occasion. Half of the applicants (30/60) were expected to provide enough details about the process, the time, and the stages of their self-realization, but no one was considered successful. Specifically, a gay man from Togo "was vague and did not clearly state how and when he realized his sexual orientation and on what occasion." A gay man from Pakistan "did not have a descriptive style about his experience of self-awareness from which it could be concluded that he was referring to an actual experience." A gay man from Gambia who analyzed in his interview that he was arrested and tortured by the police in Gambia due to his SO, showing during the interview his injuries and submitting medical documents about it, was disbelieved because, inter alia, he was not able to explain on what occasion he realized his SO, when exactly and provide details about the experience. A gay man from Guinea was not able to describe "how he experienced the shift in his $\mathrm{SO}$ and how this affected his life since." A gay man from Bangladesh could not provide enough details about " $[\mathrm{h}]$ ow he realized his $\mathrm{SO}$, how this changed his life and how this affected his perception about romantic relationships." In addition, as it was mentioned above, although a gay man from Cameroon provided details about how he used to be sexually stimulated when he was playing with other boys, or when he was dreaming of having sex with a man, "he was not able to elaborate on his inner process which, in a hostile environment towards LGBTI, is governed by negative feelings, neither was in a position to describe his feelings."

According to GAS' practice, applicants were expected to have passed through the process of self-realization in their puberty and have their first relationships at an early age. In six cases, applicants were disbelieved because they expressed their nonconforming sexuality later in their life. A lesbian woman from Cameroon was unable to explain "why she realized her SO at 39 and not before." Similarly, a lesbian woman from DRC could not explain why she had her first same-sex sexual contact at her 30s. The narrative of a gay man from Cameroon was found non-credible because, even though he realized his $\mathrm{SO}$ at the age of thirteen, he had his first relationship at the age of twenty. On the other hand, a gay man from Gambia was not believed because even though he had his first contact at 18 , he realized his SO two years later. The applicant explained that his first contacts were not regular and he realized that he is "actually gay" only after starting a relationship with his boyfriend. This explanation was found "weak" and the applicant "unable to clarify the contradiction."

These adjudications of GAS were governed by the idea that the discovery and expression of SO which takes place earlier in life, follows a certain process and has different stages, rather than being unique for each person. The theory of a realization process of one's SO that consists of specific stages, such as confusion, tolerance, and acceptance, has been so widely suggested during the previous decades that "it has infused popular consciousness, shaping our expectations of the 'natural' progression of sexual identity formation" (Berg and Millbank, 2009). However, these theories have received strong criticism: as Berg and Millbank pointed out, the majority of relevant research has been conducted on white, middle-class men in the US with little consideration of expressions of minority sexualities in non-Western contexts, especially among women (Berg and Millbank, 2009; Rowen 
and Malcolm, 2002). According to researches on the topic, even within the US, men from ethnic minorities differed from both white men and from one another, in terms of the process of realizing and expressing their SO, making it highly ambiguous that there could be a universal realization process, applicable to asylum seekers coming from different ethnicities, genders, social classes, races, and religions (Berg and Millbank, 2009). This assumption that all asylum seekers' experiences fit in the pattern: desire-confusion-denial-acceptance-formation of an identity is problematic, does not leave space to consider applicants' subjectivity and the complexity of their experiences, and can lead to unjust decisions (Giametta, 2017). As the current survey highlights there are applicants, mainly women, who realized their same-sex attraction at a later stage in life, others who never expressed openly their SO, or applicants who have never felt confused with their sexuality.

\section{Shame, Difference, and the Truth From the Suffering Body} Pursuant to the DSSH model, realizing their SO is a hard process for LGB+ asylum seekers that involves different stages. As it is specifically described, "perceiving and understanding difference is usually a long and painful process" and "there may often be important turning points or milestones" (Hungarian Helsinki Committee et al., 2015). The realization of SO is perceived as a "painful journey," accompanied by negative feelings that "may lead to self-denial” (Hungarian Helsinki Committee et al., 2015; Chelvan, 2013).

Following the above guidelines, applicants were asked to elaborate on their feelings of difference and shame during the realization and acceptance procedure. In 11 cases, applicants were asked to elaborate on their difference and express their negative feelings about their experiences and themselves, but no one was considered successful. A gay man from Nigeria "was unable to clarify how he perceived his sexual difference." A gay man from Benin "was not able to elaborate on his feelings of difference and provide information about the time of self-discovery." A gay man from Bangladesh "could not prove a lived experience of difference." A lesbian woman from Cameroon "had no difficulty in the acceptance of her SO." A gay man from Iraq was not able to establish his credibility since "the discovery of sexual identity is a focal point in the life of every human being, especially when it deviates from the socially acceptable rule. Certainly, this process is governed by a lot of tough and hard emotions. However, none of this internal process is reflected in the applicant's responses."

Based on the stereotypical idea that the more homophobic is the society, the more different and abnormal would feel the individual (Hertoghs and Schinkel, 2018; Giametta, 2017; Saleh, 2020; Jansen, 2018), applicants were expected to have passed through an inner struggle, to have developed negative feelings about themselves and to have felt different in their countries, in order to be believed. Applicants' sexuality was expected to affect their perception of themselves and to be accompanied by a feeling of abnormality, to be considered genuine. Consequently, applicants' accounts that were accompanied by feelings of pleasure and joy for their sexuality and deviated from the model of a "painful journey," were assessed by GAS as non-credible. Indicatively, in the case of a gay man from Iran, the applicant was disbelieved because "no difficulty or hardship was reflected in his answers." During his interview, although he expressed that he could not live openly in Iran, he explained that he did not feel negative emotions about himself and his same-sex sexuality. Specifically, he stated: "I never thought that what I was doing was wrong. The only thing that was wrong, was the country that I used to live in." This approach, on the one hand, obscures applicants' experiences, since not all refugees are moving from oppression and death to progress and freedom, but their realities are more complex, and on the other hand, it further enhances a simplistic dichotomy between West as a geography of progress and East as a place of backwardness, where sexual minorities have no other choice than suffering (Shakhsari, 2014). This homonationalist perception excludes experiences that do not fit under the narrowly defined narrative of difference, shame, and oppression and can lead to unjust assessments.

\section{Silencing Women's Experiences}

The practices implemented by GAS do not seem to always correspond to women's experience. Even though in the 2015 revision of the DSSH model it was clearly mentioned that the experience of difference can come earlier or later, which is a significant improvement, it is still mentioned that "often sexual awakening occurs in childhood, for example a young boy playing games with the girls rather than the boys" (Hungarian Helsinki Committee et al., 2015; Chelvan, 2013; Dawson and Gerber, 2017). The question with regards to women, especially in male-dominated societies, is how many women would actually have such experiences of difference to narrate, given the fact that even from childhood their societal role is strictly predetermined? As a lesbian woman from Cameroon stated in her interview "I never thought about it [my SO] in my teenage years [...] I don't know why." Out of nine women's cases studied for the needs of the survey, seven were already married when they submitted their asylum application. Even though previous marriage was not always clearly mentioned as a reason for disbelief in the reasoning-only in three out of seven cases it was referred to explicitly-applicants were asked to explain why they have been married and their justification was often met with disbelief. Indicatively, a lesbian woman from Iraq was asked twice in her interview "What was the reason that you had a traditional marriage with a man, since you already felt as a lesbian since your teenage years?" and in another part "Why are you still married with a man?"

According to literature, many same-sex attracted women realize their attraction in adulthood, after having been married and having children (Dawson and Gerber, 2017; Jansen, 2018). However, according to the study, this was assessed as a basis for non-credibility. A lesbian woman from Cameroon was unable to explain why she discovered her same-sex attraction in her 39 and a lesbian woman from DRC in her 30s. This factor, in combination with women's invisibility in their countries of origin due to patriarchal structures, renders the public expression of their SO harder (Giametta, 2017; Lewis, 2014; Nasser-Eddin et al., 2018). In contrast to men, whose sexuality 
is in general socially accepted as open and public, women's sexuality belongs to the private sphere and it is often oppressed even when it is heterosexual (Blackwood and Wieringa, 2007). In many cases, nonheterosexual women applicants do not have experiences of romantic or sexual relationships with women that were publicly expressed in a way that led them to deviate from the traditional role of women in their society (Shuman and Bohmer, 2014). As a married lesbian woman from DRC explained in her interview, "I had never had the chance to go out, in a bar or a nightclub with my girlfriend. I had never been attacked or received any threat." Despite the fact that the applicant burst to tears in different points of the interview, which reveals the crucial condition of her mental health, she had no experience of external harm to provide. Although it is a sign of even more severe oppression, the fact that due to complete invisibility, women often have nothing but a "heterosexual narrative" to present, raises the "burden of proof" to demonstrate their SO (Dawson and Gerber, 2017). Despite the fact that not having experiences of harm due to sexual orientation does not render their accounts non-credible according to the DSSH model, these women, unlike men, would need to depend solely on the narration of their inner emotional difference to establish credibility regarding their SO, which is a much more demanding process than it is to narrate lived experiences of difference and harm in public sphere, especially for working-class people. This lack of relevant provisions within the DSSH to comply with women's experiences puts women applicants at a disadvantage, causing unfair consequences on their credibility's examination.

\section{Ignoring the Intersection of Sexuality With Class}

According to the survey only four applicants out of 60 had completed secondary school and followed undergraduate studies. Twenty-four applicants attended school for less than $12 \mathrm{yr}$, eight for less than $9 \mathrm{yr}$ and 24 for less than $6 \mathrm{yr}$. This is a different landscape than the one in many other European countries where asylum seekers have obtained a higher level of education (Andrade et al., 2020). A possible explanation of this phenomenon is that in general Greece is not considered a desirable destination among refugees and consequently refugees who belong to an upper social class can afford the longer journey toward richer countries.

In 20 out of 24 cases of the applicants who had not completed primary school, the reasons of rejection contained their inability to provide details about the experience of awareness of their SO, and to express their feelings about their difference and toward their partners. Even though urban and educated LGB+ applicants may express themselves using Western terms and notions about homosexuality because they have been exposed to Western ideas, working-class, same-sex attracted individuals, whose voices are rarely heard cannot always fit their experiences in such expectations (Blackwood and Wieringa, 2007; Jansen, 2018; UKLGIG, 2018). According to this research, applicants who have not completed compulsory education faced difficulties either to understand the meaning of vague notions and constructions as "self-awareness" and "self-realization" or to express themselves and provide sophisticated and elaborated narratives about these procedures. Specifically in 7 cases, applicants did not primarily understand what a process of selfrealization is. Answers such as "I don't understand" or "What do you mean" followed the question to describe their process of selfrealization. In such cases, even though describing facts could be easier, it is much more difficult to provide accounts about their feelings and their inner process. Moreover, it could be argued that this process disproportionately disadvantages applicants who do possess the educational background to speak English, as it would be nearly impossible for them to have been familiarized with western ideas around sexual orientation to correspond to these culturally targeted questions. As Lewis observes, the ability to speak well and present a credible account are limited to class and social mobility (Lewis, 2014).

According to the study, GAS's expectations for an account to be considered credible do not cover only the content of the narrative, but also the way and the language a story was told, by failing to recognize the intersections of class, gender, race, and religion which produce exclusions (Giametta, 2017; Shuman and Bohmer, 2014).

\section{Means of Evidence}

As was analyzed above (see section 4.2), in the use of evidence we could also distinguish between two generations of decisions. During the first period, applicants used to submit photos and videos and undergo medical and psychological examinations to prove their sexual orientation (Jansen and Spijkerboer, 2011). Such practices were condemned by the CJEU in the $A, B$ and $C$ judgment. According to the CJEU and UNHCR, applicants should not be expected to provide pieces of evidence such as films and photos of a sexual nature or being obliged or urged to undergo medical tests (UNHCR, 2012). ${ }^{23}$ As it is stated in the $A, B$ and $C$ judgment, demanding this sort of evidence would infringe applicants' dignity, does not necessarily have probative value, and would incite other applicants to do so. Amongst the files analyzed, in just one case, involving a gay man from Iraq, there was a submission of photos of sexual nature. These photos were not taken into account because, according to the case worker, they did not have probative value.

Although the exclusion of this sort of evidence from the credibility assessment is undoubtedly welcomed and applicants should never be expected to provide them, CJEU's guidelines seem to have been misunderstood by domestic authorities, who tend to refuse the submission of any kind of visual material (UKLGIG, 2018). In two cases out of the 60 analyzed, applicants were not allowed to provide on their own will visual evidence and photos during the interview. In the first case the applicant was about to submit a screenshot of his conversation with his father where the latter was threatening him and in the second the applicant would like to submit photos of himself and his partner that were uploaded in Iran's social media.

Notwithstanding the fact that in principle the CJEU's prohibition of assessing material about sexual acts in credibility assessment is a safeguard for LGB+ asylum seekers'

\footnotetext{
${ }^{23}$ Joint cases C-148, C-149 and C-150/13 (n 11) paras 65-66.
} 
rights, it should have been interpreted that this prohibition does not cover non-pornographic evidence and materials that are already public in the country of origin (ICJ, 2016; Jansen, 2018). As in the rest of asylum applications, where the applicants can submit a photo from their marriage or from their common life to prove the family bond, LGB+ asylum seekers should be able to use such means of evidence. The acceptance of such evidence is of high importance, taking into account the fact that in their home countries applicants do not have the possibility of getting married or of forming a civil partnership, and, therefore, of using official documents to prove their relationships.

\section{A "When-Oriented" Approach}

Another practice that was observed in the study was the tendency of the case workers to orient the examination around certain facts and incidents, in many cases not crucial to the applicant's story, to identify small inaccuracies in the narrative and, as a result, to conclude that the stated events did not happen. According to UNHCR handbook "untrue statements by themselves are not a reason for refusal of refugee status and it is the examiner's responsibility to evaluate such statements in the light of all the circumstances of the case" (UNHCR, 1979). However, this practice was observed in 15 cases (one quarter of the cases). In one of them, an applicant, who was diagnosed with Posttraumatic Stress Disorder (PTSD), was not believed because, among others, at one point of the interview she stated that she was raped around twelve o'clock and in another around two o'clock. This confrontational practice fails to establish a friendly and reassuring atmosphere for the asylum seeker, so as to enable them to express themselves, and shows complete indifference toward their psychological condition and the traumatic experiences they have passed through either in their home countries or in the reception centers in Greece.

According to literature, there are more than one well-justified explanations for this phenomenon. Research on memory for distressing events demonstrates that peripheral experiences are more likely to be nonaccurately recalled rather than core experiences (Millbank, 2009b). Furthermore, traumatic experiences can severely impact applicants' ability to present their claim in a credible way (Struthers, 2020; Mrazova, 2019). According to EASO's guide "when interviewed twice about a traumatic event, people were inconsistent in their recall of all types of details" (EASO, 2018). Finally, the long waiting period between the applicant's arrival and their interview, in hotspots, under inhumane conditions, affects applicants' psychological condition and consequently their ability to present their story (Human Rights Watch, 2017). This practice proves that case workers fail to comprehend the limits of the procedure and seem to perceive their role as the one of an investigator, whose duty is to discover the truth. However, in refugee law where the benefit of the doubt is one of the main principles, this perception would inevitably lead to misjudgments (Millbank, 2009b). Case workers should recognize that they may be mistaken in their conclusions and could never definitely establish the facts of a case. In contrast, a perception of their roles as estimators who are trying to balance possibilities and resolve the doubts in favor of the applicant is closer to the limitations of the procedure (Rehaag and Evans Cameron, 2020).

\section{Other Practices}

In five other cases, the applicants' SO was assessed as noncredible without any examination of their internal credibility. In such cases, the rejection was entirely arbitrary, without the provision of reasoning in the decision. In the case of a gay man from Pakistan, the credibility of his account was not established because he was not in a position to provide more details about his "sexual orientation and his gender identity which do not correspond to his sex," even though during the interview the applicant did not mention anything about his GI. In the same decision it is stated that "sexual orientation is a conscious choice" about one's life. In this case, it was more than obvious from the file that the decision-maker lacked even the basic understanding about SOGI. Furthermore, in a case of a lesbian woman from Iraq that arrived in Greece with her husband, her claim that she is attracted to women was assessed by the case worker as "irrelevant" to her main claim about domestic violence and her SO was rejected as non-credible without any further reasoning.

In two other cases, the applicant's account was found noncredible because, among other factors, the legislation in the country of origin was not actually applied. Even though it is strongly supported by the author that mere criminalization should be a sufficient condition for the establishment of the well-founded fear, the examination of the internal credibility precedes the examination of the well-founded fear and these two distinct stages of examination could not merge into one. In one more case, in which the applicant was finally granted asylum in the second instance, even though he was believed about being gay by GAS, he was not believed as facing a well-founded fear of persecution, since in Iran he could be discreet about his SO and he had never been the victim of an attack. It could be argued, regarding these practices, that the examination of the wellfounded fear (in the case of criminalization) and the persecution (in the case of discretion requirement) at the stage of credibility assessment is more than just a consequence of lack of appropriate training and knowledge of the case workers around SO matters. This practice is compounded by the tendency to use accelerated procedures since rejecting an account as non-credible exempts case workers from examining other elements of the refugee definition and requires less justification and country of origin information research.

From 2016, and especially after the implementation of the EUTurkey statement, according to which applications lodged in the five hotspot islands are examined through an accelerated border procedure with fewer guarantees, concerns are raised by different national and international actors about the conformity of first instance decisions with quality standards (AIDA: Greek Council for Refugees, 2020). The United Nations Special Rapporteur on the human rights of migrants highlighted that the asylum law provisions at the Greek borders raise "serious concerns over due process guarantees." (OHCHR, 2017). Relevantly, the GAS director declared in 2016 that GAS has received high pressure which led to "reduce our standards and minimize the guarantees 
of the asylum process." (AIDA: Greek Council for Refugees, 2020).

Furthermore, and according to UNHCR with regards to the quality of first instance asylum decisions, not only in border but also in regular procedure, "while the quality of first instance examination remains largely in line with international and European recommended standards and procedural safeguards, UNHCR has observed a deterioration in quality at first instance as a result of the pressure resulting from the large pending caseload [...] Applications are being examined as fast as possible by a team of case workers, many of whom are new and not sufficiently trained and supported locally" (AIDA: Greek Council for Refugees, 2020). These general comments about the quality of the decisions, as it is also shown by the current survey, raise serious concerns about unjust outcomes in the examination of $\mathrm{SO}$ asylum claims, especially considering the particularity of these claims and the inherent challenges that emerge in credibility assessment even in more effective and inclusive asylum systems (Gustafsson Grønningsæter, 2017; Jansen, 2018; UKLGIG, 2018; Gröndahl, 2020).

\section{CONCLUSION}

Despite increasing elaboration on the issue of credibility assessment in SO asylum claims in a European and international level and the establishment of guidelines and prohibited methods, GAS uses practices to assess credibility that do not respect the applicants' right to self-identification, are potentially harmful, and lead to unjust outcomes. Such practices can be divided into two types: On the one hand, practices that are not consistent with the CJEU's interpretation of EU law and UNHCR guidelines, such as the questions around sexual practices of the applicant, the extensive use of (firstgeneration) stereotypes, the denial to receive applicants voluntarily submitted non-pornographic evidence, the extreme emphasis on the exact time of the events, and the lack of a legal reasoning in the decisions. The use of such unlawful practices seems inevitable, but still reproachable, in a system where the main objective is the acceleration of asylum applications' examination and the limitation of refugee flows. On the other hand, the study has shown extensive use of practices that at first sight are in conformity with international and domestic guidelines for credibility assessment, which were described in this article as second-generation stereotypes, and are expectations about applicants' inner processes that stem from the notion that there is a universal experience shared among all LGB+ applicants. Second-generation stereotypes constitute a rejecting reason for the majority of the cases studied, reflecting the lack of individual assessment, which deprives the method from any of its probative value and illustrates the need for revised guidelines by advisory bodies and agencies such as UNHCR and EASO, in which SO will be seen through an intersectional approach.

These practices include, inter alia, an identity-based perception of $\mathrm{SO}$, as something more than sexual practices, which is an important part of the applicant's personhood, and the expectation of the applicants to have passed through a painful linear process of self-realization accompanied with feelings of difference and shame. The typical reasoning of the unable-toprovide-details-about-their-feelings-and-experiences applicant is clearly observable as a leitmotif in more than the half of the negative decisions, often with no further analysis. The study showed that these expectations do not always correspond to applicants' experiences, while being disproportionately difficult to women and people from lower social classes to provide such narratives.

The application of this proposed model of credibility assessment presents important limitations. First, this series of stereotypical notions around sexual minorities obscures the diverse lived experiences and subjectivities of the applicants, jeopardizing their right to self-identification and unfairly excluding applicants who do not conform with these predispositions of the authorities. Second, it fails to take into account the intersections of sexuality with gender, class, ethnicity, and race, echoing patriarchal structures and neoliberal principles by promoting the narratives of men from higher social classes. Similarly, this homonationalist system that expects from the applicants to have experiences of difference, shame, and suffering to present enhances a dichotomy between progress and backwardness. Additionally, the proposed model is founded on an outdated essentialist perception of identity that ignores the relevant queer, feminist and postcolonial theories. Last, by universalizing applicants' experiences, this model fails to correspond to the legal obligation of an individualized asylum claims' examination.

The necessity of relevant guidelines' revision is not only a theoretical debate about epistemic violence, but has material consequences in applicants' lives, who by failing to prove their credibility become deportable to their countries of origin. Although the author condemns the very idea of a model that evaluates the truth of someone's sexuality, in the current context of asylum applications a process of credibility assessment seems practically inevitable. In this sense, it is proposed that the applicant's self-identification should consist of an important element for the procedure, as it constitutes the defining element of someone's sexuality. Moreover, it should be recognized that the cultural background of the caseworkers constitutes a limitation of the procedure and deprives the authorities of their alleged objectivity and impartiality; the benefit of the doubt should therefore be applied in the course of credibility assessment, and, on the other hand, extensive trainings of caseworkers aim to improve their cross-cultural and gendered understanding of sexuality. Lastly, it seems of major significance that relevant research by individuals with lived experiences of nonconforming sexuality in applicants' countries of origin is promoted to enrichen this dialogue.

\section{DATA AVAILABILITY STATEMENT}

The data analyzed in this study is subject to the following licenses/ restrictions: The dataset includes asylum interview transcripts and first-instance decisions, which contain sensitive information. 
Requests to access these datasets should be directed to SZ, szisakou@gmail.com.

\section{ETHICS STATEMENT}

Ethical review and approval was not required for the study on human participants in accordance with the local legislation and institutional requirements. The patients/ participants provided their written informed consent to

\section{REFERENCES}

AIDA: Greek Council for Refugees (2020). Country Report: Greece: 2019 Update. Available at: https://www.asylumineurope.org/reports/country/greece/statistics (Accessed December 20, 2020).

Andrade, V. L., Danisi, C., Dustin, M., Ferreira, N., and Held, N. (2020). Queering Asylum in Europe: A Survey Report. Available at: https://www.sogica.org/ database/andrade-danisi-dustin-ferreira-and-held-queering-asylum-in-europea-survey-report-2020/.

Avgeri, M. (2021). Trans*it: Transgender and Gender Nonconforming Asylum Claimants' Narratives in Greece. Sexualities, 0 (0), 1-15. doi:10.1177/ 13634607211013278

Berg, L., and Millbank, J. (2009). Constructing the Personal Narratives of Lesbian, Gay and Bisexual Asylum Claimants. J. Refugee Stud. 22 (2), 195-223. doi:10.1093/jrs/fep010

Blackwood, E., and Wieringa, S. E. (2007). "Globalization, Sexuality, and Silences: Women's Sexualities and Masculinities in an Asian Context," in Women's Sexualities and Masculinities in a Globalizing Asia. Editors S. E. Wieringa, E. Blackwood, and A. Bhaiya (New York: Palgrave MacMillan), 1-20. doi:10.1057/9780230604124_1

Boellstorff, T. (2005). Between Religion and Desire: Being Muslim and Gay in Indonesia. (Cham: Spinger), Am. Anthropologist 107 (4), 575-585. doi:10.1525/ aa.2005.107.4.575

Butler, J. (1990). Gender Trouble: Feminism and the Subversion of Identity. New York: Routledge. 1999.

Butler, J. (2005). Giving an Account of Oneself. New York: Fordham University Press. doi:10.5422/fso/9780823225033.001.0001

BVMN (2020). The Black Book of Pushbacks. Available at: https://www. borderviolence.eu/launch-event-the-black-book-of-pushbacks/. Vol. I.

Cass, V. C. (1979). Homosexual Identity Formation: A Theoretical Model. J. Homosexuality 4, 219-235. doi:10.1300/j082v04n03_01

Chlvan, S. (2014). "C-148/13, C-149/13 and C-150/13, A, B and C v. Staatssecretaris van Veiligheid en Justitie: Stop Filming and Start Listening - a judicial black list for gay asylum claims". Available at: https://europeanlawblog.eu/2014/12/12/c14813-c-14913-and-c-15013-a-b-and-c-v-staatssecretaris-van-veiligheid-enjustitie-stop-filming-and-start-listening-a-judicial-black-list-for-gay-asylum-claims/ (Accessed July 14, 2020).

Chelvan, S. (2013). “The Assessment of Credibility of Women, Victims of Torture Within the Decision Making Process and Whether This Is Reflected in Appeal Outcomes" (Home Affairs Committee). Available at: http://www.publications. parliament.uk/pa/cm201314/cmselect/cmhaff/71/71vw32008_HC71_01_VIRT_ HomeAffairs_ASY-35.htm (Accessed July 14, 2020).

Dave, N. N. (2011). Indian and Lesbian and what Came Next: Affect, Commensuration, and Queer Emergences. Am. Ethnol. 38 (4), 650-665. doi:10.1111/j.1548-1425.2011.01328.x

Dawson, J., and Gerber, P. (2017). Assessing the Refugee Claims of LGBTI People: Is the DSSH Model Useful for Determining Claims by Women for Asylum Based on Sexual Orientation? Int. J. Refugee L. 29 (2), 292-322. doi:10.1093/ijrl/ eex022

EASO (2018). Evidence and Credibility Assessment in the Context of the Common European Asylum. Available at: https://op.europa.eu/en/publication-detail/-/ publication/6ad7488b-ba25-11e8-99ee-01aa75ed71al (Accessed June 14, 2020). participate in this study. Written informed consent was obtained from the individual(s) for the publication of any potentially identifiable images or data included in this article.

\section{AUTHOR CONTRIBUTIONS}

The author confirms being the sole contributor of this work and has approved it for publication.

ECRE (2020). Greece: Pushbacks Continue, Eviction of Makeshift Camp in Athens. Available at: https://www.ecre.org/greece-pushbacks-continue-eviction-ofmakeshift-camp-in-athens/ (Accessed December 20, 2020).

ECRE (2017). Preliminary Difference: The Impact of Judgments of the Court of Justice of the EU in Cases X.Y.Z, A.B.C. And Cimade and Gisti on National Law and the Use of the EU Charter of Fundamental Rights. Available at: https:// www.ecre.org/wp-content/uploads/2017/03/CJEU-study-Feb-2017-NEW.pdf (Accessed June 25, 2020).

Elliston, D. A. (1995). Erotic Anthropology: "ritualized Homosexuality" in Melanesia and Beyond. Am. Ethnol. 22 (4), 848-867. doi:10.1525/ ae.1995.22.4.02a00100

European Council (2016). EU-Turkey Statement. Available at: https://www consilium.europa.eu/en/press/press-releases/2016/03/18/eu-turkey-statement/ (Accessed March 18, 2016).

Human Rights Watch: Cosse, Eva (2020). Greece Is Still Denying Migrant Pushbacks. Available at: https://www.hrw.org/news/2020/08/21/greece-stilldenying-migrant-pushbacks (Accessed December 20, 2020). doi:10.1515/ 9781478005131

Foucault, M. (1978). The History of Sexuality. New York: Pantheon Books.

Fuss, D. (1989). Essentially Speaking, Feminism, Nature and Difference. New York: Routledge.

Giametta, C. (2017). The Sexual Politics of Asylum. New York: Routledge. doi:10.4324/9781315561189

Gomez, E. (2014). The Post-ABC Situation of LGB Refugees in Europe. Emory Int. L. Rev. 30 (3), 475-500. (Accessed June 20, 2020).

Gröndahl, A., and RFSL (2020). Avslagmotiveringar I HBTQI-Asylarended. Available at: https://www.sogica.org/database/grondahl-avslagsmotiveringari-hbtqi-asylarenden-2020/.

Gustafsson Grønningsæter, A. (2017). "Establishing a Sexual Identity: The Norwegian Immigration Authorities Practice in Sexuality-Based Asylum Cases," in Out \& Proud? LGBTI asylum in Europe Conference COC Netherlands, Amsterdam, October 5-6, 2017. Available at: https://www.coc. $\mathrm{nl} / \mathrm{wp}$-content/uploads/2017/04/Norwegian-practices-Andrea-GustafssonGronningsaeter.pdf.

Gyulai, G., Singer, D., Chelvan, S., Given-Wilson, Z., and Zoe, S. (2015). Credibility Assessment in Asylum Procedures, a Multidisciplinary Training Manual. (Budapest: Hungarian Helsinki Committee). Available at: https://www. refworld.org/docid/5582addb4.html. Vol. 2.

Hertoghs, M., and Schinkel, W. (2018). The State's Sexual Desires: The Performance of Sexuality in the Dutch Asylum Procedure. Theor. Soc. 47, 691-716. doi:10.1007/s11186-018-9330-x

Human Rights Watch (2017). "EU/Greece: Asylum Seekers' Silent Mental Health Crisis". Available at: https://www.hrw.org/news/2017/07/12/eu/greece-asylumseekers-silent-mental-health-crisis (Accessed December 20, 2020).

ICJ (2016). Refugee Status Claims Based on Sexual Orientation and Gender Identity - A Practitioners' Guide. Available at: http://www.refworld.org/ docid/56cabb7d4.html (Accessed July 12, 2020).

Jansen, S. (2014). Good Practices Related to LGBTI Asylum Applicants in Europe. Available at: https://www.ilga-europe.org/resources/ilga-europe-reports-andother-materials/good-practices-related-lgbti-asylum-applicants.

Jansen, S., and COC Netherlands (2018). Pride or Shame: Assessing LGBTI Asylum Applications in the Netherlands Following the XYZ and ABC Judgments. Available at: https://www.refworld.org/docid/5c6eb3344.html (Accessed June $25,2020)$. 
Jansen, S., and Spijkerboer, T. (2011). Fleeing Homophobia, Asylum Claims Related to Sexual Orientation and Gender Identity in Europe. Amsterdam: VU University. Available at: https://www.refworld.org/ docid/4ebba7852.html.

Katyal, S. (2002). Exporting Identity. Yale J. L. Feminism 14 (1), 97-176. doi:10.2139/ssrn.330061

Lewis, R. A. (2014). "Gay? Prove it": The Politics of Queer Anti-deportation Activism. Sexualities 17 (8), 958-975. doi:10.1177/1363460714552253

Lewis, R. A., and Naples, N. A. (2014). Introduction: Queer Migration, Asylum, and Displacement. Sexualities 17 (8), 911-918. doi:10.1177/1363460714552251

Malichudis, S., Achilleas, S., and Costas, K. (2020). "Labeled "Immigrants", TwoThirds of Moria's Population Actually Have a Refugee Profile". Available at: https://wearesolomon.com/mag/on-the-move/labeled-immigrants-two-thirdsof-morias-population-actually-have-a-refugee-profile/ (Accessed January 26, 2020).

Ramón Mendos, L. (2019). State-Sponsored Homophobia. Available at: https://ilga. org/state-sponsored-homophobia-report-2019.

Millbank, J. (2009b). 'The Ring of Truth': A Case Study of Credibility Assessment in Particular Social Group Refugee Determinations. Int. J. Refugee L. 21 (1), 1-33. doi:10.1093/ijrl/een040

Millbank, J. (2009a). From Discretion to Disbelief: Recent Trends in Refugee Determinations on the Basis of Sexual Orientation in Australia and the United Kingdom. Int. J. Hum. Rights 13 (2-3), 391-414. doi:10.1080/ 13642980902758218

Ministry of Migration and Asylum (2021). Pakistan and Bangladesh, Safe Countries of Origin. Available at: https://migration.gov.gr/en/asfaleis-choreskatagogis-to-mpagklantes-kai-to-pakistan/ (Accessed January 26, 2020).

Mrazova, A. (2019). "Legal Requirements to Prove Asylum Claims Based on Sexual Orientation: A Comparison between the CJEU and ECtHR Case Law," in Maryna Shevtsova and Denise Venturi. Editor A. Güler (Cham: Spinger), 185-207. doi:10.1007/978-3-319-91905-8_10

MSF (2019). MSF Statement about Access to Healthcare for Asylum Seekers and Undocumented People in Greece. Available at: https://msf.gr/sites/default/files/2_ msf_statement_about_access_to_healthcare_in_greece_20191218_final_4_track_ changes_0.pdf.

Nasser-Eddin, N., Abu-Assab, N., and Abu-Assab, A. (2018). Reconceptualising and Contextualising Sexual Rights in the MENA Region: beyond LGBTQI Categories. Gend. Develop. 26 (1), 173-189. doi:10.1080/13552074.2018.1429101

OHCHR (2017). "Report of the Special Rapporteur on the Human Rights of Migrants on His mission to Greece". A/HRC/35/25/Add.2. Available at: https:// www.refworld.org/docid/593a8b8e4.html (Accessed December 20, 2020).

Rehaag, S., and Evans Cameron, H. (2020). Experimenting with Credibility in Refugee Adjudication: Gaydar. Can. J. Hum. Rights 9 (1). Available at: https:// digitalcommons.osgoode.yorku.ca/scholarly_works/2801 (Accessed December 20, 2020).

Ricard, N. (2014). Testimonies of LGBTIQ Refugees as Cartographies of Political, Sexual and Emotional Borders. Jls 3 (1), 28-59. doi:10.1075/jls.3.1.03ric
Rowen, C. J., and Malcolm, J. P. (2002). Correlates of Internalized Homophobia and Homosexual Identity Formation in a Sample of Gay Men. J. Homosex 43 (2), 77-92. doi:10.1300/j082v43n02_05

RSA (2020). Moria Nightmare: Briefings Detention and Reception Conditions EUTurkey Statement Hotspots Unaccompanied and Separated Children. Available at: https://rsaegean.org/en/moria-nightmare/.

Saleh, F. (2020). Queer/Humanitarian Visibility: The Emergence of the Figure of the Suffering Syrian Gay Refugee. Middle East Critique 29 (1), 47-67. doi:10.1080/19436149.2020.1704501

Shakhsari, S. (2014). The Queer Time of Death: Temporality, Geopolitics, and Refugee Rights. Sexualities 17 (8), 998-1015. doi:10.1177/1363460714552261

Shuman, A., and Bohmer, C. (2014). Gender and Cultural Silences in the Political Asylum Process. Sexualities 17 (8), 939-957. doi:10.1177/ 13634607145522610.1177/1363460714552262

Struthers, K. (2020). "LGBTI Refugee Protection in a Culture of Disbelief: The Impact of Integration” RLI Working Paper. Available at: https://sas-space.sas.ac.uk/9429/ (Accessed December 20, 2020).

UKLGIG (2018). Still Falling Short. Available at: http://www.sogica.org/database/ uklgig-still-falling-short-2018/ (Accessed June 25, 2020).

UNHCR (1979). Handbook on Procedures and Criteria for Determining Refugee Status and Guidelines on International Protection under the 1951 Convention and the 1967 Protocol Relating to the Status of Refugees. Available at: https:// www.refworld.org/docid/5cb474b27.html (Accessed June 25, 2020).

UNHCR (2012). Guidelines on International Protection No. 9: Claims to Refugee Status Based on Sexual Orientation And/or Gender Identity within the Context of Article 1A (2) of the 1951 Convention And/or its 1967 Protocol Relating to the Status of Refugees. Available at: http://www.refworld.org/docid/50348afc2. html (Accessed June 25, 2020).

UNHCR (2020). UNHCR Calls on Greece to Investigate Pushbacks at Sea and Land Borders with Turkey. Available at: https://www.unhcr.org/news/briefing/ 2020/6/5ee33a6f4/unhcr-calls-greece-investigate-pushbacks-sea-land-bordersturkey.html (Accessed June 25, 2020).

UNHCR (2013). Written Observations of the United Nations High Commissioner for Refugees in the Cases of A and Others (C-148/13, 149/13 and 150/13). Available at: https://www.refworld.org/docid/5215e58b4.html. (Accessed June $25,2020)$.

Conflict of Interest: The author declares that the research was conducted in the absence of any commercial or financial relationships that could be construed as a potential conflict of interest.

Copyright $\odot 2021$ Zisakou. This is an open-access article distributed under the terms of the Creative Commons Attribution License (CC BY). The use, distribution or reproduction in other forums is permitted, provided the original author(s) and the copyright owner(s) are credited and that the original publication in this journal is cited, in accordance with accepted academic practice. No use, distribution or reproduction is permitted which does not comply with these terms. 